DR. ANTOINE JAQUET (Orcid ID : 0000-0002-3426-9492)

Article type : Rapid Communication

Handling Editor: Stanislas Pol

\title{
Hepatitis B treatment eligibility in West Africa: uncertainties and need for prospective cohort studies
}

\author{
Antoine Jaquet ${ }^{1,2}$, Marcellin Nouaman ${ }^{3}$, Judicaël Tine ${ }^{4}$, Aristophane Tanon ${ }^{5}$, Camille Anoma ${ }^{6}$, André \\ Inwoley $^{7}$, Alain Attia ${ }^{8}$, Didier K. Ekouevi ${ }^{1,2,3,9}$, Moussa Seydi ${ }^{4}$, François Dabis ${ }^{1,2}$, Gilles \\ Wandeler ${ }^{4,10,11}$
}

1. Univ. Bordeaux, Inserm, Bordeaux Population Health Research Center, UMR 1219, Bordeaux, France

2. Inserm, ISPED, Bordeaux Population Health Research Center, UMR 1219, Bordeaux, France.

3. Programme PACCI, CHU de Treichville, Abidjan, Cote d'Ivoire

4. Service de maladies infectieuses et tropicales, CRCF, CHU de Fann, Dakar, Senegal

5. Service de maladies infectieuses et tropicales, CHU de Treichville, Abidjan, Cote d'Ivoire

6. ONG Clinique de Confiance d'Abidjan, Abidjan, Cote d'Ivoire

7. CeDReS, CHU de Treichville, Abidjan, Cote d'Ivoire

8. Service de hépato-gastroentérologie, CHU de Yopougon, Abidjan, Cote d'Ivoire

9. Département de Santé Publique, Faculté des Sciences de la santé, Université de Lome, Lome, Togo

10. Department of Infectious Diseases, Bern University Hospital, University of Bern, Switzerland

11. Institute of Social and Preventive Medicine, University of Bern, Switzerland

Corresponding author : Antoine Jaquet, $\mathrm{MD}, \mathrm{PhD}$

Centre de Recherche INSERM U. 1219

Institut de Santé Publique, Epidémiologie et Développement (ISPED)

Université de Bordeaux, 33076 BORDEAUX Cedex - FRANCE

Tel: 33 (0)5 57579537 Fax: 33 (0)5. 57.57.45.28 E-mail: antoine.jaquet@u-bordeaux.fr

This article has been accepted for publication and undergone full peer review but has not been through the copyediting, typesetting, pagination and proofreading process, which may lead to differences between this version and the Version of Record. Please cite this article as doi: 10.1111/liv.13484

This article is protected by copyright. All rights reserved. 


\section{Key points}

- While the World Health Organization recently recommended universal screening for HBV infection in all high-prevalence countries, there is an urgent need to document the proportion of HBV-infected patients in need of immediate treatment in sub-Saharan Africa

- Our findings suggest that only a limited proportion (10\%) of HBs antigen positive individuals are eligible for immediate antiviral therapy

- Marked difference in treatment eligibility were reported across settings underlining the need for more studies on treatment eligibility to plan access to care in West Africa

- Over half of patients were in need of close monitoring, supporting HBV universal testing and the need for prospective cohort studies

\section{List of abbreviations}

Hepatitis B virus (HBV), sub-Saharan Africa (SSA), Tenofovir disoproxil fumarate (TDF), World Health Organization (WHO), Men who have sex with men (MSM), Hepatitis C virus (HCV), Alcohol Use Disorders Identification Test (AUDIT), Alanine aminotransferase (ALT), aspartate aminotransferase (AST), viral load (VL), interquartile range (IQR), liver stiffness measurement (LSM).

\section{Competing interest: none}

\section{Funding}

The National Cancer Institute (NCI), the Eunice Kennedy Shriver National Institute of Child Health \& Human Development (NICHD), the National Institute of Allergy and Infectious Diseases (NIAID), the National Institute of Drug Abuse (NIDA) (grant $n^{\circ}$ 5U01AI069919). GW was supported by a fellowship from the Swiss National Science Foundation (PZ00P3_154730). 


\begin{abstract}
Background \& Aims

While universal screening of hepatitis B virus (HBV) is recommended in high burden countries, little is known about the proportion of HBV-infected persons in need of antiviral therapy in these settings.
\end{abstract}

\title{
Methods
}

Prisoners in Senegal and Togo, as well as female sex workers and men who have sex with men in Cote d'Ivoire were screened for HBV infection. All HBsAg-positive participants underwent transient elastography, alanine aminotransferase (ALT) and HBV viral load quantification. Individuals with liver cirrhosis or those aged $>30$ years with an HBV replication $\geq 20000 \mathrm{IU} / \mathrm{ml}$ and elevated ALT were considered eligible for antiviral therapy.

\section{Results}

Of 1256 participants, 110 (8.8\%) were HBsAg-positive; their median age was 30 years [interquartile range: $25-33$ ] and $96(86.5 \%)$ were men. Three individuals $(2.7 \%)$ had liver cirrhosis while 28 (29.5\%) of 94 participants with available measurements had an HBV viral load $\geq 20000 \mathrm{IU} / \mathrm{ml}$. Overall, $11(10.0 \%)$ subjects were considered eligible for immediate antiviral treatment; $2.1 \%$ of participants in Dakar, 7.7\% in Abidjan and 21.6\% in Lome (p=0.001) and $59(53.4 \%)$ for close monitoring due to the presence of significant liver fibrosis, elevated ALT or significant HBV replication.

\section{Conclusions}

Among vulnerable populations in West Africa, a minority of HBV-infected individuals were eligible for immediate antiviral therapy. Prospective cohort studies are necessary to evaluate anti-HBV treatment eligibility facing the significant proportion of individuals with active chronic HBV infection.

Keywords: Hepatitis B virus, Antiviral treatment, Africa

This article is protected by copyright. All rights reserved. 


\section{Introduction}

Hepatitis B virus (HBV) infection is highly endemic in sub-Saharan Africa (SSA) and bears a high burden of liver disease (1). Despite the availability of an efficient vaccine against HBV infection, universal access to this prevention strategy is challenging in SSA (2). While HBV therapy is still out of reach for most HBV-infected individuals globally, progress towards universal access to these drugs is underway. Tenofovir disoproxil fumarate (TDF), an antiviral drug recommended and widely used in first-line treatment for HIV infection is also highly active against HBV infection and is now accessible as a generic drug at fairly low cost. Considering the new recommendations by the World Health Organization (WHO) to screen the general population for HBV infection in all high-prevalence countries, there is a need to document the proportion of HBV-infected patients in need of treatment (3). This is particularly true among vulnerable populations in West Africa where high HBV prevalence was previously reported (4). Our aim was to estimate the proportion of patients eligible for antiviral therapy among a sample of HBV-infected inmates, female sex workers (FSW) and men who have sex with men (MSM) in West Africa.

\section{Methods}

\section{Study population and data collection}

We included all individuals diagnosed with an HBV infection in a cross-sectional prevalence study among vulnerable populations in West Africa. Inmates incarcerated in state prisons in Lome, Togo (September - October 2013) and Dakar, Senegal (April - May 2014) were initially recruited (5). FSW and MSM were subsequently recruited in a dedicated clinic located in Abidjan, Cote d'Ivoire (November 2014 - April 2015) (6). Inmates were randomly selected based on a cluster sampling approach using the prison cell as the statistical unit as previously described (5). FSW and MSM were randomly selected using a systematic 
sampling approach. The sampling frame was the list of patients planned to attend the center on the days of inclusion. Considering a sampling interval $\mathrm{k}=$ number of participants to be included/number of people listed to attend, monitors were asked to select among the first $\mathrm{k}$ patients and consecutively include the following patients by applying this predetermined sampling interval. All participants were screened for HBV, hepatitis C virus (HCV) and HIV infection. If screened positive for $\mathrm{HBV}$ and/or $\mathrm{HCV}$ infection, participants were referred to a referent infectious disease unit in Lome, Dakar or Abidjan for a free specialized consultation. All HIV-infected participants were referred to the HIV national treatment facility but were excluded from the analysis. All participants provided a signed informed consent. The study is in compliance with the Helsinki Declaration and was approved by the national ethic committees of Côte d'Ivoire, Senegal and Togo.

\section{General characteristics}

Standardized questionnaires were administered in French or local language by nurses or site medical staff through face-to-face interviews. Socio-demographic data included age, sex and place of residence. Alcohol use was estimated using the Alcohol Use Disorders Identification Test (AUDIT) tool (7). We used the standard cut-off of 8 points to characterize hazardous drinking. Information on present or past history of injection drug use was also collected.

\section{Laboratory measurements}

Viral hepatitis infections were assessed using rapid diagnostic tests: Determine ${ }^{\circledR}$ (Alere, Waltham, MA, United States of America (USA)) for HBs antigen and Oraquick ${ }^{\circledR}$ (Orasure, Bethlehem, PA, USA) for anti-HCV antibodies (8). Anti-hepatitis delta virus (HDV) antibodies were measured with the ETI-AB-DELTA-2® (DiaSorin S.A., Antony, France). Alanine aminotransferase (ALT) and aspartate aminotransferase (AST) were measured and reported in international units (IU) per L. A high AST level was defined as a value $>40 \mathrm{IU} / \mathrm{L}$ 
and a high ALT level if $\geq 30 \mathrm{IU} / \mathrm{L}$ in men or $\geq 19 \mathrm{IU} / \mathrm{L}$ in women according to WHO recommendations (9). HBV viral load (VL) quantification was performed using the COBAS(R) AmpliPrep/COBAS(R) TaqMan(R) v2.0 (Roche®) kit in Dakar and Abidjan and the ABBOTT M2000RT (Abbot ${ }^{\circledR)}$ kit in Togo. An HBV VL $\geq 2000 \mathrm{IU} / \mathrm{ml}$ was considered clinically significant and a value $\geq 20000 \mathrm{IU} / \mathrm{ml}$ a high viral load, as suggested in the European and WHO guidelines for the management of chronic HBV infection $(9,10)$. HBV genotype was determined using an in-house assay at the virology unit in Abidjan.

\section{Transient elastography}

All participants were assessed for liver fibrosis using a portable transient elastography device (Fibroscan 402®, Echosens, Paris) with an $\mathrm{M}$ probe. To be considered reliable, the examination had to include at least 10 valid measurements with an interquartile range (IQR) equal or below $30 \%$ of the median value [IQR/liver stiffness measurement (LSM) $\leq 30 \%$ ] (11). We used cut-off values of $\mathrm{LSM} \geq 7.9 \mathrm{kPa}$ for significant fibrosis and $\geq 9.5 \mathrm{kPa}$ for cirrhosis, as recently proposed in a validation study from The Gambia and Senegal (12).

\section{Treatment eligibility}

Based on the latest WHO recommendations, a simplified definition of treatment eligibility was applied to this $\mathrm{HBV}$-infected population; patients presenting with cirrhosis using transient elastography or with an HBV VL $\geq 20000 \mathrm{IU} / \mathrm{ml}$ combined with an abnormal ALT level) and aged >30 years were considered eligible, regardless of any other elements (9). Patients presenting at least one of the following elements; (i) HBV viral replication $\geq 2000$ IU/ml, (ii) significant fibrosis ( $\geq$ F2 METAVIR score based on transient elastography) (iii) abnormal ALT level were considered eligible for close monitoring.

This article is protected by copyright. All rights reserved. 


\section{Results}

Of the 1396 pre-included participants (786 inmates, 610 FSW or MSM), 140 were excluded (refusal $n=51$, transferred or lost before the end of the study $n=31$, unreliable LSM $n=25$, indeterminate/unknown $\mathrm{HBV}, \mathrm{HCV}$ or HIV status $\mathrm{n}=28$ and age $<18$ years $\mathrm{n}=5$ ). Of the remaining 1256 included participants, infection with HBV was documented in 130 patients (10.3\% [95\% confidence interval (CI) 8.7 - 12.0]) with significant difference between Lome (10.9\% [95\% CI 7.7 - 14.2]), Dakar (14.1\% [95\% CI 10.4 - 17.8]) and Abidjan (7.8\% [95\% CI $5.6-10.0])(\mathrm{p}=0.01)$. Among HBV-infected patients, 20 subjects co-infected with HIV were excluded.

A total of $110 \mathrm{HBV}$-infected patients were included; 37 in Lome, 47 in Dakar and 26 in Abidjan. Their median age was 30 years [interquartile range: 25-33] and 96 (86.5\%) were men (Table 1, supporting information). A total of $46(41.8 \%)$ subjects presented with an elevated ALT level, $11(10.0 \%)$ with significant fibrosis and three (2.7\%) with a cirrhosis. Of the 94 individuals with an available HBV VL, 28 (29.5\%) had a value $\geq 20000 \mathrm{IU} / \mathrm{ml}$ and nine $(9.6 \%)$ a value between $2000 \mathrm{IU} / \mathrm{ml}$ and $20000 \mathrm{IU} / \mathrm{ml}$. One patient tested positive for anti-HCV antibodies in Abidjan.

Overall, $11(10.0 \%) \mathrm{HBV}$-infected patients were considered eligible for immediate antiviral treatment (Figure 1). Anti-HBV treatment eligibility varied across countries with a proportion of $2.1 \%$ in Dakar, $7.7 \%$ in Abidjan and $21.6 \%$ in Lome $(\mathrm{p}=0.001)$. HBV treatment eligibility was more likely to be met by men $(10.5 \%)$ compared to women $(7.1 \%)$ although not significantly different $(\mathrm{p}=0.06)$. Overall, 59 (53.6\%) subjects had a significant liver fibrosis and/or significant HBV viral replication and/or elevated ALT levels, classifying them as in need for a close monitoring of their HBV infection.

This article is protected by copyright. All rights reserved. 
HBV genotype was characterized in 65 cases. Genotype E was the most frequent genotype identified $(n=52)$, followed by genotype A $(n=12)$ and genotype D $(n=1)$ with significant differences across countries (Table 1). The 52 patients harboring HBV genotype E were significantly more likely to have a high HBV VL ( $\geq 20000 \mathrm{IU} / \mathrm{ml})$ compared to those with genotype A $(50.0 \%$ vs. $16.7 \%, \mathrm{p}=0.03)$. Eight $(8.9 \%)$ of 89 patients tested for anti-HVD antibodies had a positive result.

\section{Discussion}

We provide one of few estimation of antiviral treatment eligibility among HBV-infected patients in SSA. Only $10 \%$ of HBsAg-positive participants were eligible for antiviral treatment based on WHO guidelines (9). However, over half of individuals had at least one criteria for close monitoring, which highlights the need for HBV screening in the general population of high-prevalence countries.

Our HBV treatment eligibility estimates were consistent with those from a recent study conducted in the Gambia, where $4.4 \%$ of HBV-infected individuals from a community sample and $9.7 \%$ of blood donors were eligible for antiviral therapy (13). In our study, the proportion of individuals with a treatment indication was higher in Togo than in the other settings, mainly due to the high proportion of participants with a high HBV VL. Although the reason for this difference is unknown, a potential explanation could be the HBV genotype distribution: patients with genotype E were more likely to be eligible for anti-HBV treatment compared to those with a genotype A. As previously reported, genotype E was the most predominant type in the three participating countries (14). However, almost half of patients presented with a genotype A in Senegal, in line with previous reports $(15,16)$. Estimating the distribution of HBV genotypes has public health and clinical implications as previous reports identified HBV genotype as a predictor of clinical events (17). Over one-half of HBV- 
infected participants were in need of close monitoring, highlighting the need for larger, prospective assessments to document the dynamics of treatment eligibility over time.

Our study population constituted of HBV-infected subjects screened among vulnerable populations may not be representative of the general population in West Africa. Although these groups were identified as vulnerable to viral hepatitis through high-risk sexual behaviors or intravenous drug use in high-income countries, HBV acquisition generally occurs at birth or during early childhood in SSA. In line with these observations, prevalence of HBV infection in our study was consistent with the prevalence in the general population from Cote d'Ivoire, Togo and Senegal (1). The lower prevalence of HBV-infected patients reported in Côte d'Ivoire was potentially related to demographic characteristics as the carriage of chronic HBs antigen was reported to be associated with male gender (13). The WHO recommendations used to assess treatment eligibility are a compromise based on limited access of diagnostic and treatment capacity. Therefore, the use of other international guidelines might provide significant differences in treatment eligibility. Applying the latest European guideline criteria for HBV treatment initiation resulted in seven patients $(6.3 \%)$ eligible to immediate treatment, confirming the low rate of immediate treatment eligibility (10). The cross-sectional assessment of treatment eligibility might have led to the underestimation of the proportion of individuals eligible for antiviral therapy. For example, we were unable to assess the presence of persistent ALT elevation over time.

This article is protected by copyright. All rights reserved. 


\section{Conclusion}

In this sample of $\mathrm{HBV}$-infected persons across West Africa only a minority were eligible to anti-HBV treatment but over half had signs of active infection. As access to antiviral treatment for HBV infection is likely to improve in highly endemic regions, better estimates of the true proportion of patients eligible to treatment from longitudinal studies are needed to inform policy and plan access to care.

\section{References}

1. SCHWEITZER A, HORN J, MIKOLAJCZYK R T, KRAUSE G, OTT J J. Estimations of worldwide prevalence of chronic hepatitis B virus infection: a systematic review of data published between 1965 and 2013. Lancet 2015; 386(10003): 1546-55.

2. BEKONDI C, ZANCHI R, SECK A, et al. HBV immunization and vaccine coverage among hospitalized children in Cameroon, Central African Republic and Senegal: a crosssectional study. BMC infectious diseases 2015; 15: 267.

3. Guidelines on Hepatitis B and C Testing, policy brief. World Health Organization, Geneva, 2016. avaialble at: http://apps.who.int/iris/bitstream/10665/251330/1/WHO-HIV2016.23-eng.pdf?ua=1 [last accessed 03/14/2017].

4. ADJEI A A, ARMAH H B, GBAGBO F, et al. Prevalence of human immunodeficiency virus, hepatitis B virus, hepatitis C virus and syphilis among prison inmates and officers at Nsawam and Accra, Ghana. Journal of medical microbiology 2006; 55(Pt 5): 593-7.

5. JAQUET A, WANDELER G, TINE J, et al. HIV infection, viral hepatitis and liver fibrosis among prison inmates in West Africa. BMC infectious diseases 2016; 16: 249.

This article is protected by copyright. All rights reserved. 
6. NOUAMAN M, JAQUET A, TANON A, et al. Infection à ViH et fibrose hépatique chez des travailleuses du sexe et des hommes ayant des rapports sexuels avec d'autres hommes à abidjan, Côte d'ivoire [French]. Oral communication [abstract $\left.\mathrm{n}^{\circ} \mathrm{S} 16.02\right]$, 8th AFRAVIH congres, 20-23 April 2016. Brussel, Belgium.

7. SAUNDERS J B, AASLAND O G, BABOR T F, DE LA FUENTE J R, GRANT M. Development of the Alcohol Use Disorders Identification Test (AUDIT): WHO Collaborative Project on Early Detection of Persons with Harmful Alcohol Consumption--II. Addiction 1993; 88(6): 791-804.

8. NJAI H F, SHIMAKAWA Y, SANNEH B, et al. Validation of rapid point-of-care (POC) tests for detection of hepatitis B surface antigen in field and laboratory settings in the Gambia, Western Africa. Journal of clinical microbiology 2015; 53(4): 1156-63.

9. Guidelines for the prevention, care and treatment of persons with chronic hepatitis B infection. Geneva, World Health Organisation 2015. available at: http://www.who.int/hiv/pub/hepatitis/hepatitis-b-guidelines/en/ [Last accessed 3/14/2017].

10. EUROPEAN ASSOCIATION FOR THE STUDY OF THE LIVER. ELECTRONIC ADDRESS E E E, EUROPEAN ASSOCIATION FOR THE STUDY OF THE L. EASL 2017 Clinical Practice Guidelines on the management of hepatitis B virus infection. Journal of hepatology 2017; [ahead of print].

11. BOURSIER J, ZARSKI J P, DE LEDINGHEN V, et al. Determination of reliability criteria for liver stiffness evaluation by transient elastography. Hepatology 2013; 57(3): 118291.

12. LEMOINE M, SHIMAKAWA Y, NAYAGAM S, et al. The gamma-glutamyl transpeptidase to platelet ratio (GPR) predicts significant liver fibrosis and cirrhosis in patients with chronic HBV infection in West Africa. Gut 2016; 65(8): 1369-76.

This article is protected by copyright. All rights reserved. 
13. LEMOINE M, SHIMAKAWA Y, NJIE R, et al. Acceptability and feasibility of a screen-and-treat programme for hepatitis B virus infection in The Gambia: the Prevention of Liver Fibrosis and Cancer in Africa (PROLIFICA) study. The Lancet Global health 2016; 4(8): e559-67.

14. KIM B K, REVILL P A, AHN S H. HBV genotypes: relevance to natural history, pathogenesis and treatment of chronic hepatitis B. Antivir Ther 2011; 16(8): 1169-86.

15. MAYLIN S, SIRE J M, MBAYE P S, et al. Short-term spontaneous fluctuations of HBV DNA levels in a Senegalese population with chronic hepatitis B. BMC infectious diseases 2015; 15: 154 .

16. VRAY M, DEBONNE J M, SIRE J M, et al. Molecular epidemiology of hepatitis B virus in Dakar, Senegal. J Med Virol 2006; 78(3): 329-34.

17. KEW M C, KRAMVIS A, YU M C, ARAKAWA K, HODKINSON J. Increased hepatocarcinogenic potential of hepatitis B virus genotype A in Bantu-speaking sub-saharan Africans. J Med Virol 2005; 75(4): 513-21.

This article is protected by copyright. All rights reserved. 
Table 1. Characteristics of $\mathrm{HBV}$-infected persons according to their place of residence $(\mathrm{N}=110)$.

\begin{tabular}{|c|c|c|c|c|c|}
\hline & $\begin{array}{c}\text { Female sex workers/ MSM } \\
\text { Abidjan (Ivory Coast) } \\
(\mathrm{n}=26)\end{array}$ & $\begin{array}{c}\text { Inmates } \\
\text { Dakar (Senegal) } \\
(\mathrm{n}=47)\end{array}$ & $\begin{array}{c}\text { Inmates } \\
\text { Lome (Togo) } \\
(\mathrm{n}=37)\end{array}$ & $\mathbf{p}$ & $\begin{array}{l}\text { Total } \\
(\mathrm{n}=110)\end{array}$ \\
\hline Age (median, [IQR]), years & $28.5[24.5-32]$ & $31[26-37]$ & $30[26-32]$ & 0.12 & $30[25-33]$ \\
\hline Gender & & & & $<0.0001$ & \\
\hline Men & $12(46.1)$ & $47(100.0)$ & $37(100.0)$ & & $96(87.3)$ \\
\hline Women & $14(53.9)$ & $0(0.0)$ & $0(0.0)$ & & $14(12.7)$ \\
\hline Alcohol use* & & & & 0.69 & \\
\hline No/moderate use & $23(88.5)$ & 44 (93.6) & $33(89.2)$ & & $100(90.9)$ \\
\hline Hazardous drinking & $3(11.5)$ & $3(6.4)$ & $4(10.8)$ & & $10(9.1)$ \\
\hline Intravenous drug use & & & & 0.89 & \\
\hline Never & $26(100.0)$ & 46 (97.9) & $37(100.0)$ & & $109(98.9)$ \\
\hline Present/past use & $0(0.0)$ & $1(2.1)$ & $0(0.0)$ & & $1(1.1)$ \\
\hline AST (IU/L), median, [IQR] & $26[20-34]$ & $26[22-36]$ & $32.5[28-42]$ & 0.05 & $29[22-38]$ \\
\hline $\mathbf{A S T}^{* *}, \mathrm{n}(\%)(\mathrm{IU} / \mathrm{L})$ & & & & 0.16 & \\
\hline Normal & 15 (57.7) & $30(63.8)$ & $16(43.2)$ & & $61(55.5)$ \\
\hline Elevated & $11(42.3)$ & $17(36.2)$ & $21(56.8)$ & & $49(44.5)$ \\
\hline ALT (IU/L), median, [IQR] & $28.5[18-40]$ & $21[16-31]$ & $28.5[21-35]$ & 0.03 & $26[18-35]$ \\
\hline $\mathbf{A L T}^{* *}, \mathrm{n}(\%)(\mathrm{IU} / \mathrm{L})$ & & & & 0.003 & \\
\hline Normal & $9(34.6)$ & $35(74.5)$ & $20(54.0)$ & & $64(58.2$ \\
\hline Elevated & $17(65.4)$ & $12(25.5)$ & $17(46.0)$ & & $46(41.8)$ \\
\hline Transient elastography (KPa) median, [IQR] & $6.1[5.0-6.8]$ & $5.4[4.8-6.6]$ & $5.8[4.9-6.9]$ & 0.51 & $5.8[4.9-6.7]$ \\
\hline Transient elastography $\dagger(\mathrm{KPa})$ & & & & 0.59 & \\
\hline$<7.9$ & $24(92.3)$ & 44 (93.6) & $31(83.8)$ & & $99(90.0)$ \\
\hline$\geq 7.9-9.5$ & $2(7.7)$ & $2(4.3)$ & $4(10.8)$ & & $8(7.3)$ \\
\hline$\geq 9.5$ & $0(0.0)$ & $1(2.1)$ & $2(5.4)$ & & $3(2.7)$ \\
\hline HBV viral load $(\mathbf{n}=94), \mathrm{n}(\%) \mathrm{IU} / \mathrm{ml}$ & & & & 0.0003 & \\
\hline$<2000$ & $21(80.8)$ & $24(77.4)$ & $12(32.4)$ & & $57(60.6)$ \\
\hline$\geq 2000-20000$ & $2(7.7)$ & $2(6.4)$ & $5(13.5)$ & & $9(9.6)$ \\
\hline$\geq 20000$ & $3(11.5)$ & $5(16.2)$ & $20(54.1)$ & & $28(29.8)$ \\
\hline HBV genotype $(n=65), n(\%)$ & & & & 0.001 & \\
\hline $\mathrm{A}$ & $1(7.1)$ & $10(43.5)$ & $1(3.6)$ & & $12(18.5)$ \\
\hline $\mathrm{D}$ & $0(0.0)$ & $1(4.3)$ & $0(0.0)$ & & $1(1.5)$ \\
\hline $\mathrm{E}$ & $13(92.9)$ & $12(52.2)$ & $27(96.4)$ & & $52(80.0)$ \\
\hline Anti-HDV antibody (n=89), n (\%) & & & & 0.80 & \\
\hline Negative & $22(88.0)$ & $27(93$. & $32(91.4)$ & & $81(91.0)$ \\
\hline Positive & $3(12.0)$ & $2(6.9)$ & $3(8.6)$ & & $8(9.0)$ \\
\hline
\end{tabular}

This article is protected by copyright. All rights reserved. 
*Declared alcohol use during the last 12 month assessed with the Alcohol Use Disorders Identification Test (AUDIT), a threshold $>8$ was retained to define hazardous drinking **Threshold for high transaminase according to WHO guidelines: ALT $\geq 30 \mathrm{IU} / \mathrm{L}$ in men or $\geq 19 \mathrm{IU} / \mathrm{L}$ in women, AST $\geq 40 \mathrm{IU} / \mathrm{L} \uparrow$ Threshold based on a validation study performed in the Gambia among HBV mono-infected patients (Lemoine et al. GUT, 2015). Abbreviations: IQR inter quartile range, AST aspartate aminotransferase, ALT alanine aminotransferase, HBV hepatitis B virus, HDV

hepatitis D virus

This article is protected by copyright. All rights reserved. 
Figure 1. Proportion of $\mathrm{HBV}$-infected participants eligible for antiviral treatment or in need of close monitoring according to the WHO guidelines* in Lome (Togo), Dakar (Senegal) and Abidjan (Cote d'Ivoire) 2013-2015 (n=110).

* Treatment eligible: patients presenting with cirrhosis (based on a transient elastography value $\geq 9.7 \mathrm{KPa}$ ) or an $\mathrm{HBV}$ viral load $\geq 20000 \mathrm{IU} / \mathrm{ml}$ with an abnormal ALT ( $\geq 30 \mathrm{IU} / \mathrm{L}$ in men or $\geq 19 \mathrm{IU} / \mathrm{L}$ in women) if aged $>30$ years. Close monitoring considered if presence of at least one of the following elements; (i) HBV viral replication $\geq 2000 \mathrm{IU} / \mathrm{ml}$, (ii) significant fibrosis ( $\geq$ F2 METAVIR score based on transient elastography) (iii) abnormal ALT level. Deferred treatment; none of the previous elements.

†Men having sex with men, $\ddagger$ Female sex workers, JInmates

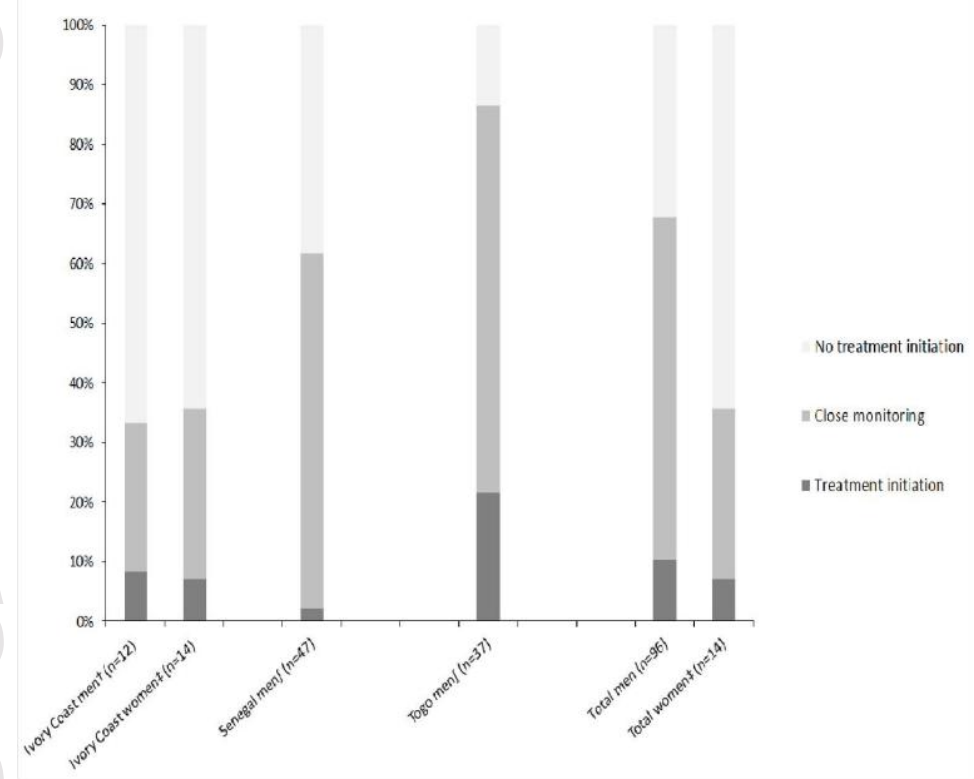

This article is protected by copyright. All rights reserved. 